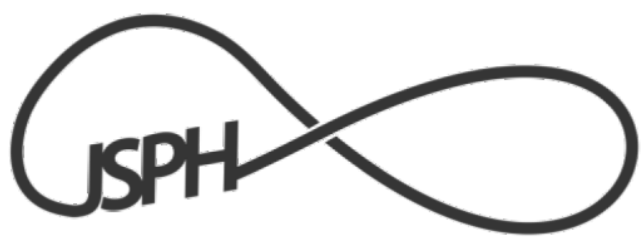

Jurnal Sosiologi Pendidikan Humanis

E-ISSN 2527-5879 P-ISSN 2527-5879

http://journal2.um.ac.id/index.php/jsph

Email: jsphum@yahoo.co.id

Volume 2, Nomor 1, Juli 2017

Halaman 9-15

\title{
STUDI ECODEVELOPMENT: KONTEKSTUALISASI PEMBANGUNAN BERKELANJUTAN DALAM “PASANG” OLEH KOMUNITAS ADAT AMMATOA
}

\author{
Ayu Adriyani \\ Penyuluhan dan Komunikasi Pembangunan, Sekolah Pascasarjana Universitas Gadjah Mada \\ Email: ayu.adriyani@mail.ugm.ac.id
}

\begin{abstract}
Abstrak
Arah pembangunan hari ini, membawa manusia harus merenung lebih dalam bahwa ada yang salah sebenarnya. Melihat pembangunan semata-mata dari sudut pandang ekonomi belum cukup mampu memberikan jaminan bahwa kebutuhan generasi yang akan datang masih akan tetap tersedia. Akhirnya, pertimbangan ekologi dan sosial tidak bisa dikesampingkan. Komunitas Adat Ammatoa Kajang di Sulawesi Selatan telah mempraktikkan pola-pola pembangunan yang tetap merawat lingkungan dan sistem sosial mereka ini. Metode yang digunakan dalam penelitian ini adalah kualitatif deskriptif. Informan dalam penelitian ini adalah Ammatoa (Pemimpin adat) dan Galla' Limbo (Kepala Desa) Tanah Towa. Penelitian ini menunjukkan bagaimana pemaknaan pesan "Pasang ri Kajang" yang terus diwariskan untuk membangun tanpa merusak lingkungan tanah adat Kajang.
\end{abstract}

Kata Kunci: Pembangunan; lingkungan; Pasang ri Kajang

\section{ECODEVELOPMENT STUDY: THE CONTEXTUALIZATION OF THE SUSTAINABLE DEVELOPMENT ON PASANG BY THE INDIGENOUS COMMUNITIES OF AMMATOA}

\begin{abstract}
How the development is going today brings us to reflect deeply that something is wrong. Though that development is only about the economic point does not quite capable to guarantee that all the needs of future generations will still be available. Finally, the ecology and social factors can not be ruled out. The indigenous communities of Ammatoa in South Sulawesi have practiced the development that does not damage the environment. The methods of this study are descriptive cualitative. The informan are Ammatoa and Galla' Limbo. This study show the meaning of the message behind "Pasang ri Kajang" to build their area without damaging the environment.
\end{abstract}

Keywords: Development; Environment; Pasang ri Kajang 


\section{LATAR BELAKANG}

Posisi pembangunan baik dari segi pertentangan teorinya maupun dari segi polemik praksisnya selalu menarik untuk dikaji secara lebih lanjut. Terlebih, Pemerintah Indonesia pada masa pemerintahan Jokowi-JK 2014-2019, sedang gencar melakukan pembukaan akses dan pembangunan infrastruktur di berbagai sektor dari Sabang hingga Merauke. Tidak hanya di Indonesia, pembangunan infra-struktur menjadi hal yang paling diusahakan terutama di Negaranegara berkembang. Pada dasarnya memang, pembangunan fisik infrastruktur menjadi yang paling mudah terlihat keberhasilannya. Di era awal pembangunan Indonesia sendiri terjebak dalam teori lingkaran setan kemiskinan (vicious circle of poverty). Dari teori inilah kemudian dikembangkan teori-teori ekonomi pembangunan. Teori-teori ini yang digunakan untuk memandang dan memecahkan masalah ekonomi dari Negara-negara yang baru saja merdeka, seperti Indonesia pada saat itu (Rahardjo, 2012). Teori kemiskinan ini menjadi sudut pandang yang digunakan oleh Negara-negara maju pada saat itu untuk menghapus kemiskinan dengan memberi modal kepada Negara-negara berkembang, dengan kata lain memberikan pinjaman (utang). Kemiskinan yang berujung pada solusi pemberian pinjaman ini, juga dikonsepkan oleh Geoge C. Marshall dan dikenal dengan Marshall Plan (Nasution, 1996).

Namun seiring berjalannya waktu, Todaro mengungkapkan bahwa ada yang salah dengan paradigma pembangunan selama ini (Dila, 2007). Pembangunan dalam hal ini senantiasa menempatkan faktor ekonomi sebagai faktor utama dan mengabaikan faktor-faktor lain. Padahal, dalam proses ekonomi untuk memproduksi barang dan jasa bagi kebutuhan masyarakat, maka dibutuhkan faktor-faktor poduksi dari kombinasi berbagai modal (capital) seperti 1) modal produksi; 2) modal manusia; 3 ) modal keuangan; 4) modal sosial; dan 5) modal alam (Hadad, 2016). Namun pada kenyataannya, iklim sinergi antara masing-masing modal tersebut tidak pernah diciptakan.

Ekonomi menjadi faktor yang senantiasa dipertuankan. Padahal, dalam banyak penelitian telah dikaji secara mendalam bahwa faktor ekonomi jika terus menerus dikejar maka akan membawa manusia sampai di titik "henti". Hal ini karena, tidak ada nilai-nilai keberlanjutan dalam sisi ekonomi. Ekonomi tidak memiliki daya untuk memastikan bahwa kebutuhan generasi mendatang masih tetap akan terpenuhi.

Konsep Pembangunan Berkelanjutan (Sustainable Development Goals) yang ditargetkan sejak 2016-2030 menggantikan Millennium Development Goals yang berakhir di
2015 menjadi angin segar terhadap pola dan praktik pembangunan. Dalam konteks pembangunan berkelanjutan, pembangunan adalah proyek jangka panjang. Olehnya, pengelolaan dan ketersediaan sumber daya alam menjadi penting untuk memaksimalkan tujuan mulia pembangunan. Pada dasarnya, SDGs memerlukan dan menuntut tiga jenis perubahan. Pertama, perubahan paradigma kebijakan (policy). Jika hutan dan sumber daya air hanya dipandang sebagai komoditas dan barang yang siap diambil, SDGs menyatakan bahwa hutan dan air merupakan barang publik yang harus dipertahankan, dilindungi, dan dilestarikan. Kedua, perubahan kelemba-gaan dan tata kerja kelembagaan, misalnya, dari tertutup menjadi terbuka , inklusif, dan partisipatif. Ketiga, perubahan pada level operasi. Kini, Indonesia telah memiliki sistem LAPOR yang membuat semua warga Indonesia bisa dengan mudah melaporkan melalui layanan pesan pendek (SMS), misalnya tentang sekolah yang ambruk atau sampah yang menumpuk (Bahagijo,2016: 47)

Tentunya, banyak pihak menaruh harapan lebih terhadap SDGs. Terlebih tahun 2015, World Meteorological Organization's State of the Global Climate Report merilis bahwa tercatat sebagai tahun paling panas dalam sejarah. Hal ini dikarenakan terjadi akumulasi penumpukan gasgas karbon di atmosfer. Sehingga jika dibandingkan dengan zaman pra-industri, suhu rata-rata bumi menjadi lebih tinggi satu derajat Celcius (Hadad, 2016). Secara umum, hal ini tentu disebabkan oleh banyak faktor, perlakuan terhadap hutan menjadi salah satunya. Bagaimana tidak, sejak pertengahan 1990-an misalnya, penebangan hutan di Kalimantan sebenarnya telah mencapai taraf kerusakan yang maksimal. Kondisi ini juga menjadikan Indonesia sebagai pengekspor asap kebakaran hutan terbesar di dunia (Aditjondro, 2003:vii).

Perbincangan mengenai kerusakan lingkungan menjadi perbincangan yang hangat, baik dalam konteks Indonesia maupun dunia global. Pemanasan global yang menjadi imbas dari kerusakan lingkungan juga semakin diwarnai dengan rentetan permasalahan lingkungan yang lain. Seperti, hilangnya mata air, kekeringan, kebakaran hutan, banjir, tanah longsor, dll. Kutanegara, dkk (2014:1) mengungkapkan bahwa dalam pembagunan, keberlangsungan hidup jangka panjang tidak lagi menjadi pertimbangan yang diperhitungkan. Alasan peningkatan kesejahteraan dalam hal ini berujung pada eksplorasi dan eksploitasi berlebihan. Kondisi lingkungan yang disaksikan hari ini adalah akumulasi perlakuan manusia dari waktu ke waktu terhadap lingkungan. 
Menaruh perhatian pada keberlangsungan manusia dan lingkungan inilah yang menunjang nilai-nilai keberlanjutan yang dimaksud oleh SDGs. Meski SDGs sebenarnya adalah gagasan yang dihasilkan dari proses pemikiran dan perundingan yang sudah cukup lama, dan kemudian sudah mulai berlaku sejak MDGs berakhir, namun SDGs masih terus menyisakan polemik. Pilar utama SDGs adalah pilar ekonomi, sosial, dan ekologi. Sedang, salah satu prinsip yang mesti diperhatikan dalam pelaksanaannya adalah meletakkan ketiga pilar utama SDGs dalam posisi dan peran yang setara, sejajar, dan seimbang dalam proses dan kebijakan pembangunan.

Meski dari segi kebijakan, pemerintah Indonesia telah mengambil peran dalam agenda bersama ini. Indonesia telah menjadikan SDGs sebagai kompas yang nilai-nilainya mulai dijabarkan dalam Rencana Pembangunan Jangka Menengah (RPJM) mulai dari tingkat nasional hingga ke tingkat desa. Namun, kerusakan lingkungan masih terus terjadi. Pembukaan akses terhadap pihak-pihak swasta ke satu lingkungan tertentu misalnya, sering kali menciptakan perlawanan dan pemberontakan baru pada masyarakat setempat. Dengan keberadaan SDGs, maka Keberpihakan pemerintah kepada masyarakat dan perhatian pemerintah terhadap keberlangsungan generasi mendatang pun dipertanyakan.

Kondisi pembangunan nasional semacam ini membuat perhatian semestinya tertuju pada bagaimana pembangunan desa dijalankan. Meski, pembangunan nasional secara makro akan tercermin dalam pembangunan desa secara mikro, namun desa tetap hadir dengan keistimewaannya dalam mengolah nilai-nilai lokalnya. Olehnya, desa yang menjadi fokus dalam penelitian ini adalah Desa Tanah Towa, Kecamatan Kajang, Kabupaten Bulukumba Sulawesi Selatan. Kajang adalah tempat bermukimnya masyarakat adat Ammatoa. Berdasarkan tempat bermukimnya, Kajang dibagi atas dua. Yaitu, Kajang Dalam dan Kajang Luar. Masyarakat Adat Ammatoa lebih tepatnya bermukim di kawasan Kajang Dalam (Sukmawati, 2015:8).

Secara kebudayaan, kawasan Kajang Dalam juga dikenal dengan Tana Kamase-masea, sedang kawasan Kajang Luar dikenal dengan Tana Kuasayya. Tana kamase-masea berarti Tanah yang Sederhana. Kesederhanan yang dimaksudkan ini adalah kehidupan yang mereka jalankan adalah kehidupan yang dijauhkan dari segala kemudahan teknologi, kenyamanan berfasilitas, lampu yang terang benderang layaknya tempat-tempat di luar kawasan mereka, dan segala hal-hal baru di luar kebiasaan mereka. Mereka meyakini bahwa cukuplah lingkungan alami dan perlakuan mereka yang tidak berlebihlebihan yang semakin membuat mereka lebih dekat degan Tau rie' a'ra'na (Tuhan yang Maha Kuasa).

Sedangkan Tana Kuasayya, adalah kawasan yang sudah terbuka denga hal-hal yang dianggap tabu oleh masyarakat di kawasan Kajang Dalam. Mereka sudah terbuka dengan teknologi, mengakrabkan diri dengan berbagai kemudahan-kemudahan yang ditawarkan oleh perkembangan zaman. Kawasan adat Kajang Dalam lah yang pada dasarnya masih menjaga nilai-nilai lokal dalam membangun daerahnya. Tana Kamase-masea kemudian menjadi prinsip hidup yang berarti Hidup dengan Sederhana.

Anre kalumannyang kalupepeang
(Kekayaan itu tidak kekal)
Nurie'a kamase-maseaji
(yang ada hanya kesederhanaan)
Angnganrena rie'
(Makan secukupnya)
Care-care na rie
(Pakaian secukupnya)
Pammalli juku'narie'
(pembeli ikan secukupnya)
Koko na rie'
(Kebun secukupnya)
Balla situju-tuju
(Rumah seadanya)

Masyarakat di kawasan adat memegang teguh Pasang ri Kajang. Pasang yang dalam bahasa setempat (konjo) berarti pesan, sedang " $r i$ Kajang" berarti "di Kajang", menunjukkan tempat. Pasang ri Kajang berarti pesan leluhur yang diturunkan di tanah Kajang. Pasang ri Kajang hadir sebagai falsafah hidup yang mengatur segala tatanan kehidupan masyarakat adat Kajang. Petikan pada paragraf sebelumnya adalah sedikit dari banyak hal yang diatur di dalamnya, tentang prinsip hidup secara sederhana dengan tidak berlebih-lebihan yang dipegang teguh oleh masyarakat adat Tanah Towa Kajang (Mappasomba \& Palammai, 2012:42).

Pasang berisi pedoman hidup untuk masyarakat Kajang, mulai dari bagaimana tata cara kehidupan keseharian (berprilaku dan bertutur) hingga pada bagaimana memanfaatkan alam tanpa merusaknya (Tika et al., 2015). Perangkat pengetahuan yang dimiliki oleh masyarakat Tanah Towa ini bersifat lokal namun mengandung nilai-nilai universal. Misalnya, Teako panra'i borongnga, punna panra'I boronga, panra to'I linoa (jangan merusak hutan, karena jika hutan dirusak, maka kehidupan manusia juga akan ikut rusak) adalah salah satu 
contoh pesan dalam pasang ri Kajang. Pesanpesan semacam ini yang mengikat masyarakat adat Ammatoa Kajang. Jika banyak hutan hari ini yang digunduli, maka di Kajang, hutan adalah kehidupan. Pasang ri Kajang telah mengatur bagaimana hutan harus dimanfaatkan, apa yang boleh dan apa yang tidak boleh dilakukan terhadap hutan. Desa Adat Tana Towa Kajang menjadi miniatur kontekstualisasi nilai-nilai keberlanjutan yang digaungkan dunia global dan juga sekaligus mematahkan asumsi bahwa menilai pembangunan cukuplah dengan kalkulasi ekonomi semata.

\section{METODE PENELITIAN}

Penelitian ini dilakukan di Desa Tanah Towa, khususnya di lingkungan kawasan adat Ammatoa. Informan dalam penelitian ini adalah Ammatoa (sebutan untuk kepala suku) dan Galla Lombo (Kepala Desa Tanah Towa). Penelitian ini menggunakan metode kualitatif deskriptif. Kualitatif digunakan untuk menggali sudut pandang objektif secara lebih optimal. Di samping itu, pendekatan kualitatif ini digunakan untuk melihat kondisi obyek penelitian secara alamiah, dimana penulis berperan sebagai instrumen kunci. Data yang diolah dalam penelitian ini adalah data primer dan data sekunder.

Data primer diperoleh penulis dari hasil observasi dan wawancara dengan Ammatoa dan Galla Lombo. Topik-topik wawancara berkisar tentang apa dan bagaimana pasang ri Kajang mengatur pola hidup masyarakat di kawasan adat untuk menghargai lingkungan. Hasil dari wawancara dan observasi kemudian dirumuskan ke dalam nilai-nilai pembangunan berkelanjutan. Adapun beberapa kutipan wawancara yang oleh Ammatoa menggunakan bahasa konjo akan dimasukkan ke dalam pembahasan dengan menggunakan bahasa Indonesia. Sedangkan, data sekunder diperoleh dari penelusuran literatur berupa penelitian terdahulu, artikel, dan bukubuku terkait.

\section{HASIL DAN PEMBAHASAN}

Pembangunan yang berwawasan lingkungan (ecodevelopment) adalah gagasan yang hadir pada pertemuan pemimpin-pemimpin dunia di tahun 1970-an. Berbicara tentang ecodevelopment, ia merupakan suatu gaya pembangunan yang, dalam setiap kawasan ekologi, membutuhkan solusi khusus bagi masalah tertentu di kawasan tersebut berdasarkan data kultural dan data ekologi serta kebutuhan jangka panjang dan mendesak. Karena itu, pembangunan berwawasan ekologi dilaksanakan berdasarkan kriteria pembangunan yang dihubungkan dengan setiap kasus tertentu, dan penyesuaian diri terhadap lingkungan memainkan peranan penting. (Sachs dalam Hettne, 2001:335)

Pengembangan Ignacy Schas di atas merupakan penegasan bahwa tidak ada makna universal untuk pembangunan. Setiap daerah memiliki daya untuk mengolah potensi di atas tanahnya masing-masing berdasarkan kebudayaannya sendiri. Terutama untuk memastikan bahwa sumber daya alam yang ada di lingkungan tersebut terjamin ketersediaannya dan mampu mencukupi kebutuhan generasi berikutnya.

Pembangunan memang seharusnya tidak bisa dimaknai seragam antara satu daerah dengan daerah yang lain. Hal ini pulalah yang dianut oleh para pemikir aliran fenomenologi yang menegaskan bahwa proses mental seseorang atau masyarakat akan menentukan arah realiatas sosial yang terbentuk, dan kesadaran mereka akan mewarnai persepsi mereka terhadap realita. Sehingga jika merujuk pada aliran ini, maka tidak mengherankan jika pembangunan menjadi sangat multi-interpretasi (Tjokrowinoto,2007:7). Olehnya, pertentangan antara apa dan bagaimana pembangunan seharusnya dijalankan tentunya cukup beralasan jika ditinjau dari perspektif ini.

Menempatkan lingkungan sebagai satu faktor yang tidak bisa dipandang sebelah mata menjadi satu bentuk pola dan praktik pembangunan yang ditemukan di kawasan adat Tanah Towa Kajang.

"Pasang itu berisikan aturan yang mengatur berbagai macam cara kita untuk menyikapi hidup dalam kehidupan sehari-hari. Mulai dari hal yang paling sederhana seperti hormat menghormati sampai kepada hal sakral seperti hukuman yang akan diterima ketika ada yang menebang pohon sembarangan" (Hasil wawancara denganAmmatoa, Pemimpin Adat tanah Kajang Dalam).

Pasang adalah bentuk akumulasi perangkat pengetahuan masyarakat Kajang yang telah terwariskan sejak turun temurun. Dalam hal ini diyakini sebagai pesan yang berisi aturan yang diturunkan oleh tau rie' a'ra'na (Tuhan yang Maha Kuasa) kepada pemimpin pertama Kajang yang kemudian disebut dengan Ammatoa. Karena pesan ini tidak dituliskan maka Ammatoa pulalah yang meneruskan dan sekaligus menjadi penuntun masyarakat Kajang untuk memaknai pasang dengan arif dalam keseharian masyarakatnya. Karena pada dasarnya, untuk itulah pasang diturunkan, menjadi pedoman hidup.

Kehadiran Ammatoa sejak pertama kali dalam sejarah yang diyakini oleh masyarakat Tanah Towa Kajang adalah sebagai seseorang yang sakral. Kehadiran Ammatoa dianggap 
menjadi perpanjangan tangan tau rie' a'ra'na untuk mengatur kehidupan di muka bumi, khususnya di Tanah Towa. Dikarenakan kesakralan inilah, kemudian membuat sosok Ammatoa sangat terjaga dari dunia luar. Orangorang yang ingin mencari tahu lebih jauh tentang tanah adat dan ingin bertemu langsung dengan Ammatoa diperkenankan untuk datang langsung ke tanah ini, namun sangat tidak diperbolehkan untuk merekam atau melakukan hal-hal yang bertujuan untuk mengabadikan wajah Ammatoa.

Karena keterbatasan akses Ammatoa terhadap dunia luar, maka dalam menjalankan tugasnya, Ammatoa dibantu oleh Galla (orang yang membantu Ammatoa dalam berbagai bidang). Misalnya, Galla' Puto dan Galla' Lombo. Galla Puto bertugas menjadi juru bicara Ammatoa, sedang Galla' Lombo bertugas untuk mengatur urusan pemerintahanan di dalam dan di luar kawasan. Posisi Galla' Lombo ini selalu dijabat oleh Kepala Desa Tanah Towa).

"Di sini, kami selalu mengedepankan musyawarah. Jika ada sesuatu yang terjadi yang berhubungan dengan kawasan adat maka musyawarah bersama tetap kami kedepankan." (Ammatoa)

"Dalam setiap agenda yang menyangkut pembangunan desa, selain kami memang berpedoman pada UU Desa, partisipasi masyarakat adat dalam menyumbang gagasan untuk pembangunan desa mereka juga tetap diberi ruang lebih. Bagaimanapun, mayoritas masyarakat kami bermukim di kawasan adat. Sehingga, kalau berbicara pembangunan maka partisipasi mereka tentu sangat dibutuhkan" (Hasil wawancara dengan Salam, Galla Lombo, Kepala Desa Tanah Towa)

Dalam merancang pembangunan desa, baik dari pemerintahan adat Tanah Towa maupun dari pemerintahan daerah sama-sama mengedepankan musyawarah. Pemerintahan adat pada dasarnya telah meyakini bersama bahwa bermusyawarah adalah perkara penting untuk memastikan bahwa keputusan yang diambil tentang sesuatu hal adalah adil (pada porsinya masing-masing) bagi seluruh masyarakat. Sedangkan pada konteks pemerintahan desa, UU No. 6 tahun 2014 tentang Desa dan Peraturan Presiden No. 2 tahun 2015 tentang Rencana Pembangunan Desa Jangka Menengah Nasional telah memberi ruang partisipatif bagi masyarakat desa untuk ikut serta dan terlibat secara aktif dalam perancangan maupun proses pembangunan di desa mereka. Selain pendekatan partisipatif, pemerintah desa juga menjabarkan Rencana Pembangunan Jangka Menengah Desa (RPJM Desa) dalam beberapa pendekatan yaitu pemberdayaan, keberpihakan pada masyarakat, terbuka, akuntabel, selektif, keberlanjutan serta proses berulang, kecermatan, dan penggalian.

Kepala Desa Tanah Towa selain memiliki fungsi pemerintahan, juga memiliki fungsi budaya. Secara struktur pemerintahan Negara, Kepala Desa Tanah Towa adalah pemimpin utama di kelas desa. Namun jika berhubungan dengan kawasan adat, maka fungsinya adalah sebagai Galla' Lombo. Dalam struktur adat, posisinya berada di bawah Ammatoa. Karena di dalam kawasan adat, Ammatoa adalah figur adat tertinggi.

Dikarena Kepala Desa memiliki dua fungsi dalam jabatan yang diemban, maka tentu kebijakan-kebijakan tentang kawasan desa dijalankan secara beriringan dengan nilai-nilai kelokalan yang dianut oleh masyarakat Kajang Dalam. Hal ini telah dilakukan sejak awal, terutama pada saat perancangan visi misi. Visi Desa Tanah Towa adalah "Mewujudkan Desa Tanah Towa yang Lebih Sejahtera, Cerdas, Adil, dan Makmur melalui Kebijakan yang Berpihak kepada Rakyat berlandaskan Nilai-nilai Agama dan Adat Istiadat serta Mewujudkan Tanah Towa Bersahaja Penuh Budaya". Visi ini yang kemudian melahirkan berbagai misi. Diantaranya, 1) Meningkatkan pembangunan fisik dan non fisik dalam rangka mewujudkan keseimbangan pembangunan, antara SDA dan SDM.; 2) Melestarikan, mengembangkan, dan membangun adat istiadat dengan mempertimbangkan nilai-nilai kearifan lokal yang menjadi pedoman dalam beraktifitas serta mengoptimalkan fungsi dan peran aktif lembaga-lembaga adat; 3) Menjamin dan mendorong usaha-usaha yang berbasis pada potensi asli desa untuk dapat mewujudkan terciptanya pembangunan di segala bidang yang berwawasan lingkungan sehingga terjadi kelangsungan usaha-usaha pembangunan yang ramah lingkungan.

Secara administratif pemerintahan dan cita-cita yang menjadi rancangan bersama dalam RPMJDes, maka arah pembangunan kawasan adat tentu telah mengarah pada nilai-nilai keberlanjutan yang termaktub dalam SDGs yang kemudian juga diadopsi oleh RPJM Nasional. Namun secara falsafah hidup, pola dan praktik pembangunan di kawasan adat Tanah Towa telah dilakukan jauh sebelum rancangan tentang pembangunan berkelanjutan mulai diwacanakan di tahun 1970-an pada forum dunia global.

Melalui pasang, masyarakat adat memahami bahwa lingkungan yang mereka jaga adalah aset mereka untuk tetap memastikan bahwa anak cucu mereka tetap bisa makan dan hidup dari alam yang mereka jaga sejak hari ini. Definisi di atas tentu masih sangat terbuka untuk berbagai pemaknaan. Namun pada dasarnya "keberlanjutan" yang dimaksud dalam konteks 
pembangunan ini adalah"kesinambungan" dan 'keadilan antar-generasi". Dalam artian, segala hal yang dilakukan untuk memenuhi kebutuhan generasi hari ini dipenuhi tanpa mengambil terlebih menghilangkan hak generasi mendatang untuk menikmatinya. Hal ini yang kemudian mendasari hadirnya tiga pilar pembangunan. Selain ekonomi, dengan memasukkan pilar ekologi dan sosial.

Di Indonesia sendiri, UU Nomor 32 tahun 2009 tentang Perlindungan dan Pengelolaan Lingkungan Hidup telah lebih dulu mengdopsi dan menuliskan ketiga pilar di atas ke dalam aspek legal formal, bahwa Pembangunan Berkelanjutan adalah upaya sadar dan terencana yang memadukan aspek lingkungan hidup, sosial, dan ekonomi ke dalam strategi pembangunan untuk menjamin keutuhan lingkungan hidup serta keselamatan, kemampuan, kesejahteraan, dan mutu hidup generasi masa kini dan masa depan. Kemudian di tahap lebih lanjut, ketiga pilar ini juga ditopang oleh tata pemerintahan yang baik, yang mampu mensinergikan program pembangunan perdesaan sesuai dengan nilai-nilai budaya dan kelokalan di daerahnya.

Sebagaimana dituangkan dalam UU Desa, tujuan pembangunan pedesaan adalah melakukan pemenuhan kebutuhan dasar, pembangunan sarana dan prasarana desa, pengembangan potensi ekonomi lokal dan pemanfaatan sumber daya alam dan lingkungan secara berkelanjutan. Tujuan pembangunan ini dilaksanakan dengan mengedepankan semangat kebersamaan, kekeluargaan, dan kegotongroyongan guna mewujudkan pengarusutamaan perdamaian serta keadilan bagi keseluruhan masyarakat.

"Dalam memasukkan sarana dan prasarana ke kawasan adat, kami tentu mempertimbangkan pasang. Misalnya masyarakat membutuhkan jembatan, kami buatkan. Meskipun jembatan yang dibuatkan adalah jembatan dari kayu atau batang pohon yang memang layak untuk ditebang. Karena tidak mungkinlah membuat jembatan dari semen apalagi aspal seperti jembatan-jembatan dengan pada umumnya" (Hasil wawancara dengan Kepala Desa Tanah Towa)

Pemaknaan terhadap pembangunan oleh pemerintah desa pada dasarnya adalah sinergi antara agenda pemerintahan dan perangkat pengetahuan lokal. Mengenai pemanfaatan sumber daya alam yang berada di kawasan adat pun tidak boleh sembarangan. Hal tersebut diatur oleh adat, termasuk pohon apa yang boleh dan tidak boleh ditebang.

Berdasarkan data yang diperoleh dari draft RPJMDes Tanah Towa, secara keseluruhan Desa Tanah Towa terdiri atas $117 \mathrm{Ha}$ lahan persawahan dan kawasan hutan seluas 331 Ha. Hutan yang pada dasarnya memang memiliki luas yang lebih besar dibandingkan bentang alam lainnya yang ada di desa Tanah Towa memiliki makna yang mendalam bagi masyarakat Kajang Dalam. Mereka meyakini bahwa: 1) boronga appariyeki Katalassang (hutan mendatangkan sumber kehidupan); 2) Boronga akkatuhoi timbusu (Hutan menjaga ketersediaan sumber mata air); 3) Boronga appambani-I bosi (hutan mendatangkan hujan); 4) Boronga appadingingi pakrasangang (hutan menyejukkan lingkungan). (Tika, dkk, 2015:22-23)

Pemaknaan dan penghargaan atas hutan sebagai paru-paru dunia telah diyakini oleh masyarakat adat Tanah Towa Kajang sejak dulu. Hal ini pulalah yang menyebabkan mereka begitu konsisten untuk menjaga lingkungan mereka. Perkara aturan-aturan dan pembuktian ilmiah mengenai lingkungan, hanyalah upaya untuk mengonfirmasi apa yang telah mereka yakini lebih dahulu. Itupun tidak mereka butuhkan. Keyakinan mereka tetap dipertahankan dengan atau tanpa pembuktian secara ilmiah (lihat gambar 1).

Kawasan hutan di Tanah Towa Kajang dibagi ke dalam dua jenis, yakni Borong Batasaya (Hutan Rakyat) dan Borong Karamasaya (Hutan Lindung Adat). Borong Batasayya menjadi hutan yang dimanfaatkan segala isinya untuk menunjang kehidupan, misal bercocok tanam dan atau mengambil kayu bakar. Sedangkan untuk keperluan pemanfaatan kayu untuk perkakas rumah di kawasan hutan ini, tetap harus meminta izin terlebih dahulu ke pemangku adat. Terlebih jika ada masyarakat yang ingin memanfaatkan kayu yang ada di dalam Borong Batasayya, yang pada dasarnya adalah hutan lindung, maka musyawarah adat harus dilakukan terlebih dahulu dengan juga memastikan bahwa: 1) Yang bermohon belum memiliki rumah;2) yang bermohon telah lebih dahulu menanam kayu untuk keperluan hajat hidup; 3) yang

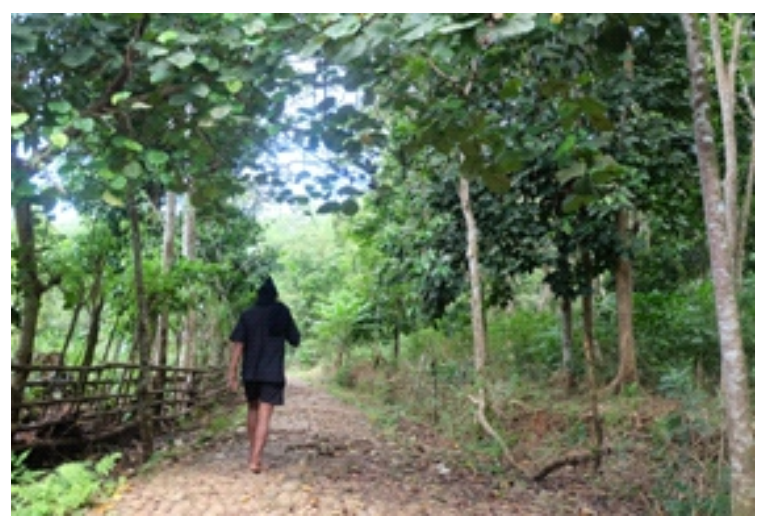

Gambar 1. Mayoritas masyarakat di Kawasan Adat masih menggunakan baju berwarna hitam dan tidak menggunakan alas kaki (Sumber: Dokumentasi pribadi) 
bermohon tidak pernah melanggar salah satu ketentuan adat; 4) yang bermohon sudah terbukti pernah menanam dan memelihara kau sebanyak dua kali lebih banyak dari jumlah pohon yang akan ditebangnya (Tika, dkk, 2015: 24)

Syarat-syarat di atas tentunya ingin menegaskan bahwa setiap orang memiliki tanggung jawab terhadap lingkungan, bahwa setiap orang bisa saja menebang pohon untuk kepentingan tertentu, namun ia juga seharusnya bertanggung jawab untuk memastikan bahwa pohon yang ditebangnya tidak mengurangi hak anak cucunya dalam memanfaatkan alam nantinya. Pemanfaatan Borong Karasayya sama sekali tidak boleh untuk kepentingan bercocok tanam. Cukuplah keberadaan Borong Batasayya untuk diambil isinya demi menunjang kebutuhan sehari-hari. Pembagian seperti ini juga menjadi turunan dari pasang yang menegaskan masyarakat untuk hidup sederhana dan tidak berlebih-lebihan dalam hidup.

Hasil bercocok tanam atau apapun yang masyarakat ambil dari borong karasayya diserahkan kepada masyarakat untuk pemanfaatannya. Baik untuk memenuhi keperluan hidup sehari-hari ataupun untuk diolah lebih lanjut agar memiliki nilai ekonomis. Misalnya saja, pemanfaatan pohon tarum yang diolah menjadi bahan baku pembuatan kain hitam yang menjadi kekhasan Tanah Towa. Kain hitam ini lah bisa mereka jual kepada orang di luar kawasan adat.

Melalui mekanisme semacam ini, masyarakat dipahamkan mengenai akses ekonomi, penghargaan terhadap lingkungan, dan kehidupan sosial yang terus dijaga. Masyarakat adat Tana Towa Kajang telah memahami lebih dahulu siklus atau rantai kehidupan dalam "membangun". Mereka meyakini bahwa kehidupan anak cucu mereka ditentukan oleh mereka yang hidup di hari ini. Olehnya, alam yang asri adalah warisan terbaik mereka.

\section{KESIMPULAN}

Jauh sebelum rumusan tentang konsep Sustainable Development Goals (SDGs) atau pembangunan berkelanjutan dirumuskan oleh dunia global dan mulai dijabarkan ke dalam rencana pembangunan, masyarakat adat Tanah Towa Kajang telah melakukan pola pada praktik pembangunan yang berkelanjutan.

Pasang ri Kajang sebagai perangkat pengetahuan lokal menjadi pedoman masyarakat adat dalam mengelolah alam, memanfaatkan hutan. Mereka meyakini bahwa hutan adalah sumber kehidupan bagi mereka dan anak cucu mereka. Olehnya, keberadaan dan ketersediaan segala sumber daya yang ada di dalam hutan harus mereka pastikan agar kehidupan anak cucu mereka tetap bisa seimbang. Tidak hanya terhadap hutan, pasang yang diyakini masyarakat Tanah Towa Kajang menjadi pedoman hidup mereka untuk menyikapi hidup secarabijaksana.

\section{DAFTAR RUJUKAN}

Bahagijo, Sugeng. (2016). Janji Sustainable Development Goals. Kebebasan, kesetaraan, dan Ekologi. Pembangunan Berkelanjutan \& Perubahan Iklim, Vol. 35, No. 2, 2016. ISSN 0301-6269

Dilla, Sumadi. (2007). Komunikasi Pembangunan. Pendekatan Terpadu. Bandung: Simbiosa Rekatama Media

Draft Peraturan Desa Nomor 6 tahun 2016 tentang Rencana Pembangunan Jangka Menengan Desa (RPJMDes) tahun 20162022 Desa Tanah Towa Kecamatan Kajang Kabupaten Bulukumba

Hadad, Ismid. (2016). Menyelamatkan bumi, menggapai tujuan pembangunan pasca 2015. perjalanan maraton menuju SDGs 2030. Pembangunan Berkelanjutan \& Perubahan Iklim, Vol. 35, No. 2, 2016. ISSN 0301-6269

Hettne, Bjorn. (2010). Teori Pembangunan dan Tiga Dunia. Jakarta: PT Gramedia Pustaka Utama

Kutanegara, Pande, Made., dkk. (2014). Membangun Masyarakat Indonesia Peduli Lingkungan. Yogyakarta: Gadjah Mada University Press

Nasution, Zulkarimen. (1996). Komunikasi Pembangunan. Pengenalan Teori dan Penerapannya. Jakarta: PT RajaGrafindo Persada

Rahardjo, M, Dawam. (2012). Pembangunan Pascamodernis. Esai-esai Ekonomi Politik. Yogyakarta: INSISTPress

Sukmawati. (2015). Pengelolaan Hutan berbasis Kearifan Lokal Adat Ammatoa. Program Studi Pendidikan Geografi Pascasarjana Universitas Negeri Malang

Tika, Zainuddin., dkk. (2015). Ammatoa. Sulawesi Selatan: Lembaga Kajian \& Penulisan Sejarah Budaya Sulawesi Selatan.

Tjokrowinoto, Moeljarto. (2007). Pembangunan. Dilema dan Tantangan. Yogyakarta: Pustaka Pelajar 